\section{Risk assessment - can we achieve consensus?}

Twetman S, Fontana M, Featherstone JDB. Risk assessment - can we achieve consensus? Community Dent Oral Epidemiol 2013; 41: 64-70. (C) 2012 John Wiley \& Sons A/S. Published by Blackwell Publishing Ltd

Abstract - Objective: The object of this conference paper was to review and discuss caries risk assessment in general practice from the questions i) 'Why', ii) 'When', and iii) 'How'. Method: Narrative review. Results: i) Patient caries risk assessment is the basic component in the decision-making process for adequate prevention and management of dental caries and for determination of individual recall intervals. ii) Caries risk assessment should always be performed at a child's first dental visit and then regularly throughout life, and especially when social or medical life events are occurring. iii) There are several risk assessment methods and models available for but the evidence for their validity is limited. Although there is no clearly superior method for predicting future caries, the use of structured protocols combining socioeconomy, behavior, general health, diet, oral hygiene routines, clinical data, and salivary tests or computer-based systems are considered best clinical practice. The accuracy ranges between $60 \%$ and $90 \%$, depending on age. Caries risk assessment is more effective in the selection of patients at low risk than those with high caries risk. Conclusion: As evidence suggests that past caries experience is far from ideal but the most important single risk component for more caries at all ages, any clinical sign of likely active demineralization on smooth, occlusal, and proximal tooth surfaces should be taken as a signal for the implementation of individually designed preventive and disease management measures.
Svante Twetman $^{1,1}$, Margherita Fontana ${ }^{2}$ and John D.B. Featherstone ${ }^{3}$

${ }^{1}$ Institute of Dentistry, Department of Cariology, Endodontics, Pediatric Dentistry and Clinical Genetics, Faculty of Health and Medical Sciences, University of Copenhagen, Copenhagen, Denmark, ${ }^{2}$ Department of Cariology, Restorative Sciences and

Endodontics, School of Dentistry University of Michigan, Ann Arbor, Michigan, USA,

${ }^{3}$ Department of Preventive and Restorative Dental Sciences, School of Dentistry, University of California, San Francisco, California, USA
Key words: Caries management; prediction; risk factors

Svante Twetman, Institute of Odontology, Faculty of Health Sciences, University of Copenhagen, Noerre Allé 20, DK-2200

Copenhagen N, Denmark

Tel: +4535326810

Fax: +4535228605

e-mail: stwe@sund.ku.dk
Caries risk assessment denotes the process of establishing the probability for an individual patient to develop new enamel or dentin lesions over the near future. The term is sometimes mixed up with caries prediction, which is the scientific/ statistical modeling of factors related to caries development in populations or defined groups of people. The validity of caries predictors is determined in prospective trials without any intervention, and the outcome is expressed in continuous values such as sensitivity, specificity, or area under ROC curves. It is important to underline that predictive values only are representative under the conditions of that specific investigation. Nevertheless, findings from predictive studies are often extrapolated to the practitioner's situation. A caries risk assessment can only be proven right or wrong, and the paradox is that the educated and skilled clinician, making a correct assessment with subsequent adequate and effective prevention, will be 'wrong'.

As caries is a biofilm-mediated multifactorial disease, it is generally understood that a comprehensive risk assessment should be based on a range of risk factors and risk indicators associated with the condition balanced against a range of protective factors the patient may be exposed to. Thus, multiple variables based on socioeconomy, behavior, general health, diet, oral hygiene, clinical observations, and past caries experience have been proposed, varying with the age group at which they are targeted (1-5). The patient is most often grouped into one of several fixed risk categories (e.g., low risk, moderate risk, and high risk). 
Previous narrative and systematic reviews have concluded that the best predictor for more future caries is previous caries experience (6-9). This is, however, far from optimal in the new era of early intervention, nonoperative, and minimal invasive caries management. The goal of this conference paper is to discuss caries risk assessment at all ages from the questions 'Why', 'When', and 'How'. The scientific context is mainly based on single predictors, risk models, or clinical programs validated in prospective clinical cohort trials and thereby disclosing a causal relationship. There are hundreds of various factors and indicators associated with caries in cross-sectional studies (10) that very well may be of relevance and importance but they are not further considered in the present paper.

\section{Why?}

Caries risk assessment has been on the agenda during the recent decade for at least four major reasons. Firstly, the ongoing caries decline has resulted in a skewed distribution of the disease, which calls for allocation of scarce or limited resources to those that need them most (11). Secondly, a risk assessment is crucial for appropriate treatment decisions concerning nonoperative and operative caries therapy $(12,13)$, and thirdly, risk grouping is used for determination of individual recall intervals (14). The fourth reason is that risk assessment forms the basis for the annual fee in countries with capitation systems (nonfee-forservice) for dental care. Depending on the risk category, the individual patient pays a yearly fee that covers all dental treatment needed; the lower the risk, the lower the price. Although the actual incitement to carry out caries risk assessment may vary from country to country and from clinician to clinician, it is our clear impression that the rational for conducting caries risk assessment is undisputed. According to literature, academics, and many dental practitioners, the assessment of risk plays an important multiple roles in modern dentistry.

\section{When?}

The question when a caries risk assessment should be carried out is not thoroughly studied, and the answer is merely based on common sense. Studies in preschool and schoolchildren indicate that approximately $50 \%$ of all participants change their risk category over a 1- to 2-year period, for better or for worse $(15,16)$. It is also very likely that the same figure is applicable in adults and fragile elderly considering the high incidence of chronic diseases, frequent use of xerogenic drugs, and natural aging. As life expectancy is increasing with an increasing number of remaining teeth, assessment of root caries risk is gaining momentum (17). There are other periods in life that may call for an increased attention to caries risk: before the eruption of the first and second permanent molars, before onset of fixed orthodontic appliances, in the beginning of pregnancy, and at onset of chronic conditions, such as diabetes or asthma. Caries risk may not only change over time in individuals but also on community level depending on socioeconomic shifts and/or as a result of population-based oral health programs. In Sweden, geo-mapping of caries risk in children has been used to allocate public resources for preventive care (18), and as a result over time, parishes initially denoted at high risk have decreased their relative caries risk in comparison with others (19).

In summary, the 'when' question can be answered with relative confidence. Caries risk assessment should be performed regularly, and at least once every second year, throughout life, and when life events that are thought to influence the balance between de- and re-mineralization are upcoming or persisting.

\section{How?}

There are numerous strategies, methods, and models available for caries risk assessment in the daily dental care. It is, however, possible to identify three main avenues: $i$ ) business as usual, ii) use of structured schemes or models, and iii) computerbased programs. Below, we have chosen some examples in each category to illustrate and comment on its strength and weaknesses.

\section{Business as usual}

It is most likely that any kind of informal risk assessment is carried out by most dentists in connection with the dental examination but this 'business as usual' is difficult to handle for the researcher. Clinical experience, knowledge, and tradition are likely to play an important part. According to a recent questionnaire, $73 \%$ of dentists reported performing caries risk assessment among children, while only $14 \%$ assessed caries 
risk by using a special form (20). Current oral hygiene, decreased salivary flow, and the presence of active caries were rated as the most important caries-related factors taken into account. Dentists in small private practice were the least likely to perform caries risk assessment, while special forms for the process were more frequently used in regions where most dentists practiced in a large group practice (20). In adults, caries risk assessment was reported in $69 \%$ of the patients but, unfortunately, there was not a strong linkage between its use and use of individualized preventive regimens (21). In Scandinavia, an analysis of dental records indicates that dentists and dental hygienists based their risk assessment in children on the past caries situation in the vast majority of the patients (22). However, as the documentation generally was poor, this does not rule out the possibility that the gut feeling or other immaterial factors might have influenced the scoring. In any case, to our knowledge, the reliability of various practice-based risk assessment processes has not been registered. Obviously, there is considerable variability in dentist's views concerning the importance of specific caries risk factors and only weak evidence that caries risk assessment is a driving force for preventive treatment.

\section{Structured protocols}

Several bodies and organizations worldwide have incorporated evidence from the literature into daily dental practice by constructing more or less complex caries risk assessment models for different age groups of patients. This has led to guidelines that aim to act as a framework for the categorization of risk level, treatment decision-making, and determination of individual recall intervals. Examples are the Carifree and CAMBRA protocols. CAMBRA stands for 'caries management by risk assessment' and is a simple clinical tool for everyday dental practice $(1,2,23)$ covered elsewhere at this meeting. Separate assessment formats are available for use by dental providers for patients age $0-5$ years (24) and patients age 6 through adult $(1,2)$. Similarly, separate risk assessment protocols for the primary, mixed, and permanent dentitions, based on clinical findings and incorporated in a caries management system, have been suggested for first visit and recall patients in general practice $(25,26)$. The CAMBRA model was recently validated in 12,954 patients over 6 years and was proven successful in accurately identifying adult patients at high and extreme caries risk (27), with the prediction for extreme risk being $88 \%$ correct.

Examples of evidence-based recommendations for single predictors of new caries or caries progression are compiled in Table 1. However, the use of risk models has generally proven more accurate than using few or single factors, and this seems especially true in children and adolescents. In a prospective study in Singapore, a sensitivity and specificity of $90 \%$ was achieved when a questionnaire, oral examination, and biological (saliva) tests were combined to predict one-year caries increment children (28). The importance of a structured interview to unveil family income and caries experience, transmission-related behavior, dietary factors, and health beliefs has been emphasized by Fontana and coworkers $(3,4)$. A risk factor model comprising ten demographic variables [exposure to fluoridation in the municipal water supply, environmental smoke exposure, race, age, locale (metropolitan versus rural), tobacco use, body mass index, insurance status, sex, and sealant application] has been validated for future caries in a public health setting (5). The average sensitivity/specificity over six years was $79 \%$ and $81 \%$. It was concluded that the model could be used as a valid instrument by school nurses/nurse practitioners, health educators, and physicians for screening of risk patients.

Practical risk assessment models for adults remain to be established. In Sweden, the Public Dental Service (PDS) has adopted guidelines for risk assessment in adults based on past and pres-

Table 1. Evidence of single-risk factors for caries risk assessment. Grading of recommendations according to the Scottish Dental Clinical Effectiveness Program: Strong $=$ Recommendation supported by strong evidence with limited bias; Weak = Recommendation supported by weak evidence with some potential for bias; Expert opinion $=$ recommendation based on expert opinion (adapted from (8)).

\begin{tabular}{lll}
\hline Variable & $\begin{array}{l}\text { Age } \\
\text { group }\end{array}$ & Recommendation \\
\hline $\begin{array}{lll}\text { Past/active caries } \\
\text { Prediction models }\end{array}$ & $\begin{array}{l}\text { All ages } \\
\text { Preschool, } \\
\text { schoolchildren }\end{array}$ & $\begin{array}{l}\text { Strong } \\
\text { Strong }\end{array}$ \\
$\begin{array}{c}\text { Diet sugar intake } \\
\text { All ages }\end{array}$ & Weak \\
Bacterial tests & All ages & Weak \\
Visible plaque/ & Toddlers, adults & Weak \\
oral hygiene & & \\
$\begin{array}{c}\text { Fluoride exposure } \\
\text { Posteruptive age, } \\
\text { 2-3 years }\end{array}$ & $\begin{array}{c}\text { Preschool children } \\
\text { teeth }\end{array}$ & Weak \\
Saliva flow rate \& & All ages & Strong \\
buffer capacity & & Expert opinion \\
\hline
\end{tabular}


ent caries, periodontal conditions, general risk, and technical risk. An example of such a scheme is shown in Table 2. The examining dentist or dental hygienist scores the risk of each individual patient into one of four risk categories ('low risk', 'some risk', 'high risk', or 'very high risk') based on this protocol, paired with their own clinical judgment. In a low-caries population consisting of 1295 young adults, the baseline agreement between this model and a more comprehensive model with saliva tests was found acceptable (78\%) for those assessed as low risk, while it was below $60 \%$ among those classified with higher risks (29). Consequently, over a 3-year period, the PDS model was proven adequate to distinguish between those with low risk from those with higher-risk categories. In elderly, root caries must be regarded as a special entity, as demineralization of cement and dentin can occur above the critical $\mathrm{pH}$ value for enamel. However, the risk variables seem to be similar; predictors frequently reported for root caries incidence were root caries prevalence at baseline, number of teeth, and plaque index according to a systematic review (17).

\section{Computer-based programs}

Cariogram is a free download software program designed to calculate the chance to avoid new car- ies lesions in the near future' (30). The interaction of ten different caries risk factors is taken into account, and the caries risk profile of the individual patient is graphically illustrated. The profile is useful for motivational interviews, and suggestions for preventive action linked to the individual profile are offered. In previous prospective trials, Cariogram has been satisfactorily validated in schoolchildren $(31,32)$ and adults or elderly (33, $34)$, while it was found less useful in younger in preschool children $(15,28)$. The sensitivity and specificity for schoolchildren is reported between $73 \%$ and $83 \%$, and $66 \%$ and $85 \%$, respectively $(7$, 32). Thus, it is important to underline that the accuracy and predictive power of computer-based risk assessment may not be significantly improved compared with, for example, past caries alone. The advantages are that attention is given to the various components affecting the caries balance, the objective consistency in risk category scoring over time, and when the assessments are made by dental personnel with different experience and background education. The graphic risk presentation is didactic and may enhance patient's understanding. Another important advantage is the improved documentation of the process in the dental records. It has been argued that the downside with the Cariogram is that the program is complex and requires

Table 2. An example of guidelines for risk assessment in adults used by the Public Dental Service in Sweden (29). Patients are categorized based on caries risk, periodontal risk, general risk, and technical risk. The highest score obtained decides the final classification and thereby a fixed fee covering the annual costs for dental care

\begin{tabular}{|c|c|c|c|}
\hline Low risk & Some risk & High risk & Very high risk \\
\hline $\begin{array}{l}\text { Caries } \\
\text { no progression last } 2 \text { yrs }\end{array}$ & $\begin{array}{l}\text { Caries } \\
\text { - progression of enamel } \\
\text { lesions within } 2 \text { yrs } \\
\text { - } 1-2 \text { new cavities }\end{array}$ & $\begin{array}{l}\text { Caries } \\
\text { - several new lesions and/or } \\
\text { progression of lesions } \\
\text { - 2-3 new cavities }\end{array}$ & $\begin{array}{l}\text { Caries } \\
\text { massive progression } \\
\mathbf{0} \geq 3 \text { new cavities } \\
\boldsymbol{\square} \text { extensive need of } \\
\text { restorative care }\end{array}$ \\
\hline $\begin{array}{l}\text { Perio } \\
\text { - healthy periodontium } \\
\text { no bleeding pockets }> \\
5 \mathrm{~mm}\end{array}$ & $\begin{array}{l}\text { Perio } \\
\text { - bleeding pockets }>5 \mathrm{~mm} \\
\text { - slight radiographic bone loss }\end{array}$ & $\begin{array}{l}\text { Perio } \\
\text { - bone loss }>1 / 3 \text { of root length } \\
\text { - initial furcation involvement }\end{array}$ & $\begin{array}{l}\text { Perio } \\
\text { - bone loss }>1 / 3 \text { of root } \\
\text { a furcation involvement }\end{array}$ \\
\hline $\begin{array}{l}\text { no radiographic } \\
\text { bone loss }\end{array}$ & & - subgingival calculus & - vertical bone pockets \\
\hline \multirow[t]{2}{*}{$\begin{array}{l}\text { General } \\
\text { no disease, medication, } \\
\text { or unfavorable habits }\end{array}$} & $\begin{array}{l}\text { General } \\
\text { - slightly compromised health }\end{array}$ & $\begin{array}{l}\text { General } \\
\text { moderate medical condition }\end{array}$ & $\begin{array}{l}\text { General } \\
\text { medical problems }\end{array}$ \\
\hline & - fear of dental treatment & $\begin{array}{l}\text { - frequent cancels or no shows } \\
\text { - communication problems }\end{array}$ & - dental avoidance \\
\hline $\begin{array}{l}\text { Technical } \\
\text { - few proximal fillings }\end{array}$ & $\begin{array}{l}\text { Technical } \\
\text { - few restorations with } \\
\text { risk of fracture } \\
\text { - deep fillings with potential } \\
\text { endodontic complications }\end{array}$ & $\begin{array}{l}\text { Technical } \\
\text { root fillings / deep fillings } \\
\text { of mixed quality } \\
\text { - risk of endo treatment }\end{array}$ & $\begin{array}{l}\text { Technical } \\
\text { - crowns/prosthetics of } \\
\text { questionable quality } \\
\text { - large treatment need }\end{array}$ \\
\hline & & - evidence of parafunction & - parafunction, bruxism \\
\hline
\end{tabular}


costly and time-consuming laboratory tests. In fact, however, the Cariogram may be useful also without salivary tests, albeit the combined sensitivity and specificity decreased markedly after exclusion of the mutans streptococci enumeration (35).

\section{Discussion}

The recent survey of practice-based caries risk assessment procedures among informed and research-interested dentists in USA and Scandinavia indicated that around $70 \%$ performed any kind of risk estimation $(20,21)$. There is, however, an obvious risk that this figure may be lower in a worldwide sample of general dentists, and the weak correlation between the risk assessment and the provided preventive care was discouraging (21). A comforting finding, however, was that recent graduates from dental school were more likely to use a caries risk assessment compared to older graduates (20). Positive changes are occurring in the development of caries risk assessment programs in US dental schools, and the transition from the surgical approach to the medical model is underway (36). We have previously argued that it is more important that a risk assessment is carried out, incorporating best available evidence, than that no attempt is made due to lack of consensus and firm evidence (8), and this statement needs to be emphasized. The important role of dental hygienists, assistants, and office staff as dental team members in the caries risk assessment process should also be stressed (37). Use of structured protocols facilitates the risk grouping in a qualityassured way, albeit more research on this topic is needed. We have data from a comparative study indicating that dental hygienists in general scored patients in a lower-risk category than dentists (29). One explanation could be that patients examined by the dental hygienists were a preselected sample of rather healthy patients. Nevertheless, this finding of difference was interesting in light of altruistic statements found in most reviews that caries risk assessment actually is more effective in selection patients at low risk than those with high caries risk. This 'negative' way to use caries risk assessment seems, however, to be adopted by few (38); most reports are still focused on finding the true high-risk individuals. A significant proportion of patients who regularly attend general dental practice have repeat examinations without any need for treatment. Thus, it would be desirable to screen out these patients out to concentrate the resources on those with greatest need.

Without doubt, the use of guidelines, structured forms, models, or computer-based programs in caries risk assessment must be regarded as 'best clinical practice' today. They provided structure to the clinical work and aid patient motivation. The use of such methods, especially when included in the electronic dental records, is in most cases straightforward, quick, and fairly objective, albeit the 'impression of the clinician' is undefined. As there is no clearly superior model, it is important to stress that any protocol actually can be used in caries management systems, such as the CAMBRA. It is also worth pointing out that given recommendations of a method by far are a guarantee that they really are followed by the dental personnel in everyday practice. Furthermore, many of the risk models have been established by prediction research undertaken in academia based on populations that may not adequately reflect the general practice environment. Furthermore, most research is carried out in children, and there is a considerable gap of knowledge concerning risk assessment in adults.

The barriers among dental personnel not to adopt the risk assessment philosophy remain obscure but can range from simple ignorance to difficulties to charge the patient or third-party payers. In this context, it is important not to unnecessarily complicate the caries risk procedure. The common comprehensive risk assessment approach may be challenged in cases where one single risk factor may be enough establish a risk category. For example, a dry mouth patient with less than $0.1 \mathrm{ml}$ of stimulated saliva per minute is always at caries risk, and the use of more sophisticated models is overkill. Likewise, as evidence suggests that past caries experience is far from ideal but the most frequently reported single risk component for more caries at all ages, any clinical sign of likely active demineralization on smooth, occlusal, and proximal tooth surfaces should be taken as a signal for the implementation of individually designed preventive and disease management measures.

\section{Conclusions}

While it should be possible to reach consensus on the 'Why' and 'When' questions, the crucial 'How' question is more complex to answer. As no single method for caries risk assessment has been proven 
superior, scientific evidence suggests that structured multifactorial models and/or computerbased program provide best clinical practice and care for patients. The extent and focus of such models may vary by the age and circumstances of the target population.

\section{Acknowledgments}

The authors have no conflict of interest to declare. MF is principal investigator of an NIH grant (1-U01-DE021412-01) called Predicting Caries Risk in Underserved Toddlers in Primary Healthcare Settings.

\section{References}

1. Featherstone JDB, Domejean-Orliguet $S$, Jenson L, Wolff M, Young D. Caries risk assessment in practice for age 6 through adult. J Calif Dent Assoc 2007;35:703-13.

2. Jenson L, Budenz AW, Featherstone JDB, Ramos-Gomez FJ, Spolsky VW, Young DA. Clinical protocols for caries management by risk assessment. J Calif Dent Assoc 2007;35:714-23.

3. Fontana M, Jackson R, Eckert G, Swigonski N, Chin $\mathrm{J}$, Zandona AF et al. Identification of caries risk factors in toddlers. J Dent Res 2011;90:209-14.

4. Fontana M, Santiago E, Eckert GJ, Ferreira-Zandona AG. Risk factors of caries progression in a Hispanic school-aged population. J Dent Res 2011;90: 1189-96.

5. Ditmyer MM, Dounis G, Howard KM, Mobley C, Cappelli D. Validation of a multifactorial risk factor model used for predicting future caries risk with Nevada adolescents. BMC Oral Health 2011;11:18.

6. Powell LV. Caries prediction: a review of the literature. Community Dent Oral Epidemiol 1998;26:36171.

7. SBU: Swedish Council on Technology Assessment in Health Care. Caries - Diagnosis, risk assessment and non-invasive treatment. A systematic review. Summary and conclusions. Report No 188, 2007. ISBN:978-91-85413-21-8.

8. Twetman S, Fontana M. Patient caries risk assessment. Monogr Oral Sci 2009;21:91-101.

9. Fontana M, Young DA, Wolff MS. Evidence-based caries, risk assessment, and treatment. Dent Clin North Am 2009;53:149-61.

10. Harris R, Nicoll AD, Adair PM, Pine CM. Risk factors for dental caries in young children: a systematic review of the literature. Community Dent Health 2004;21:71-85.

11. Nishi M, Stjernswärd J, Carlsson P, Bratthall D. Caries experience of some countries and areas expressed by the Significant Caries Index. Community Dent Oral Epidemiol 2002;30:296-301.

12. Young DA, Featherstone JD, Roth JR, Anderson M, Autio-Gold J, Christensen GJ et al. Caries management by risk assessment: implementation guidelines. J Calif Dent Assoc 2007;35:799-805.
13. Pitts N, Melo P, Martignon S, Ekstrand K, Ismail A. Caries risk assessment, diagnosis and synthesis in the context of a European Core Curriculum in Cariology. Eur J Dent Educ 2011;15(Suppl 1):23-31.

14. Patel S, Bay RC, Glick M. A systematic review of dental recall intervals and incidence of dental caries. J Am Dent Assoc 2010;141:527-39.

15. Holgerson PL, Twetman S, Stecksèn-Blicks C. Validation of an age-modified caries risk assessment program (Cariogram) in preschool children. Acta Odontol Scand 2009;67:106-12.

16. Petersson GH, Isberg PE, Twetman S. Caries risk profiles in schoolchildren over 2 years assessed by Cariogram. Int J Paediatr Dent 2010;20:341-6.

17. Ritter AV, Shugars DA, Bader JD. Root caries risk indicators: a systematic review of risk models. Community Dent Oral Epidemiol 2010;38:383-97.

18. Strömberg U, Magnusson K, Holmén A, Twetman S. Geo-mapping of caries risk in children and adolescents - a novel approach for allocation of preventive care. BMC Oral Health 2011;11:26.

19. Strömberg U, Magnusson K, Holmén A, Twetman S. Geo-mapping of time trends in childhood caries risk - a method for assessment of preventive care. BMC Oral Health 2012;12:9.

20. Riley JL 3RD, Qvist V, Fellows JL, Rindal DB, Richman JS, Gilbert GH et al. Dentists' use of caries risk assessment in children: findings from the Dental Practice-Based Research Network. Gen Dent 2010;58:230-4.

21. Riley JL 3RD, Gordan VV, Ajmo CT, Bockman H, Jackson $\mathrm{MB}$, Gilbert GB et al. Dentists use of caries risk assessment and individualized preventive for their adult patients: findings for the Dental Practice Based Research network. Commun Dent Oral Epidemiol 2011;39:564-73.

22. Sarmadi R, Gabre P, Gahnberg L. Strategies for caries risk assessment in children and adolescents at public dental clinics in a Swedish county. Int J Paediatr Dent 2009;19:135-40.

23. Young DA, Kutsch VK, Whitehouse J. A clinician's guide to CAMBRA: a simple approach. Compend Contin Educ Dent 2009;30:92-4.

24. Ramos-Gomez FJ, Crall J, Gansky SA, Slayton RL, Featherstone JDB. Caries risk assessment appropriate for the age of 1 visit (infants and toddlers). J Calif Dent Assoc 2007;35:687-702.

25. Evans RW, Pakdaman A, Dennison PJ, Howe ELC. The Caries Management System - an evidence-based preventive strategy for dental practitioners. Application for adults. Aust Dent J 2008;53:83-92.

26. Evans RW, Dennison PJ. The Caries Management System: an evidence-based preventive strategy for dental practitioners. Application for children and adolescents. Aust Dent J 2009;54:381-9.

27. Doméjean S, White JM, Featherstone JD. Validation of the CDA CAMBRA caries risk assessment-a sixyear retrospective study. J Calif Dent Assoc. 2011;39:709-15.

28. Gao XL, Hsu CY, Xu Y, Hwarng HB, Loh T, Koh D. Building caries risk assessment models for children. J Dent Res 2010;89:637-43.

29. Petersson GH, Ericson E, Isberg PE, Twetman S. Caries risk assessment in young adults using Public Dental Service guidelines and the Cariogram - a 
Twetman et al.

comparative study. Acta Odontol Scand 2012; [Epub ahead of print].

30. Bratthall D, Hänsel Petersson G. Cariogram-a multifactorial risk assessment model for a multifactorial disease. Community Dent Oral Epidemiol 2005;33:256-64.

31. Hänsel Petersson G, Twetman S, Bratthall D. Evaluation of a computer program for caries risk assessment in schoolchildren. Caries Res 2002;36:327-40.

32. Campus G, Cagetti MG, Sale S, Carta G, Lingström $P$. Cariogram validity in schoolchildren: a two-year follow-up study. Caries Res 2012;46:16-22.

33. Hänsel Petersson G, Fure S, Bratthall D. Evaluation of a computer based caries risk assessment program in an elderly group of individuals. Acta Odontol Scand 2003;61:164-71.
34. Alian AY, McNally ME, Fure S, Birkhed D. Assessment of caries risk in elderly patients using the Cariogram model. J Can Dent Assoc 2006;72:459-63.

35. Petersson GH, Isberg PE, Twetman S. Caries risk assessment in school children using a reduced Cariogram model without saliva tests. BMC Oral Health 2010;10:5

36. Yorty JS, Walls AT, Wearden S. Caries risk assessment/treatment programs in U.S. dental schools: an eleven-year follow-up. J Dent Educ 2011;75:62-7.

37. Kutsch VK, Milicich G, Domb W, Anderson M, Zinman E. How to integrate CAMBRA into private practice. J Calif Dent Assoc 2007;35:778-85.

38. Brocklehurst PR, Ashley JR, Tickle M. Patient assessment in general dental practice - risk assessment or clinical monitoring? Br Dent J 2011;210:351-4. 